$\frac{20}{3-14}-978511$

Report No.

WR-B-97-06
U.S. Department of Fnersy

Office of Inspector General

Report on

Audit of Renovation and

New Construction Projects

at Lawrence Livermore

National Laboratory

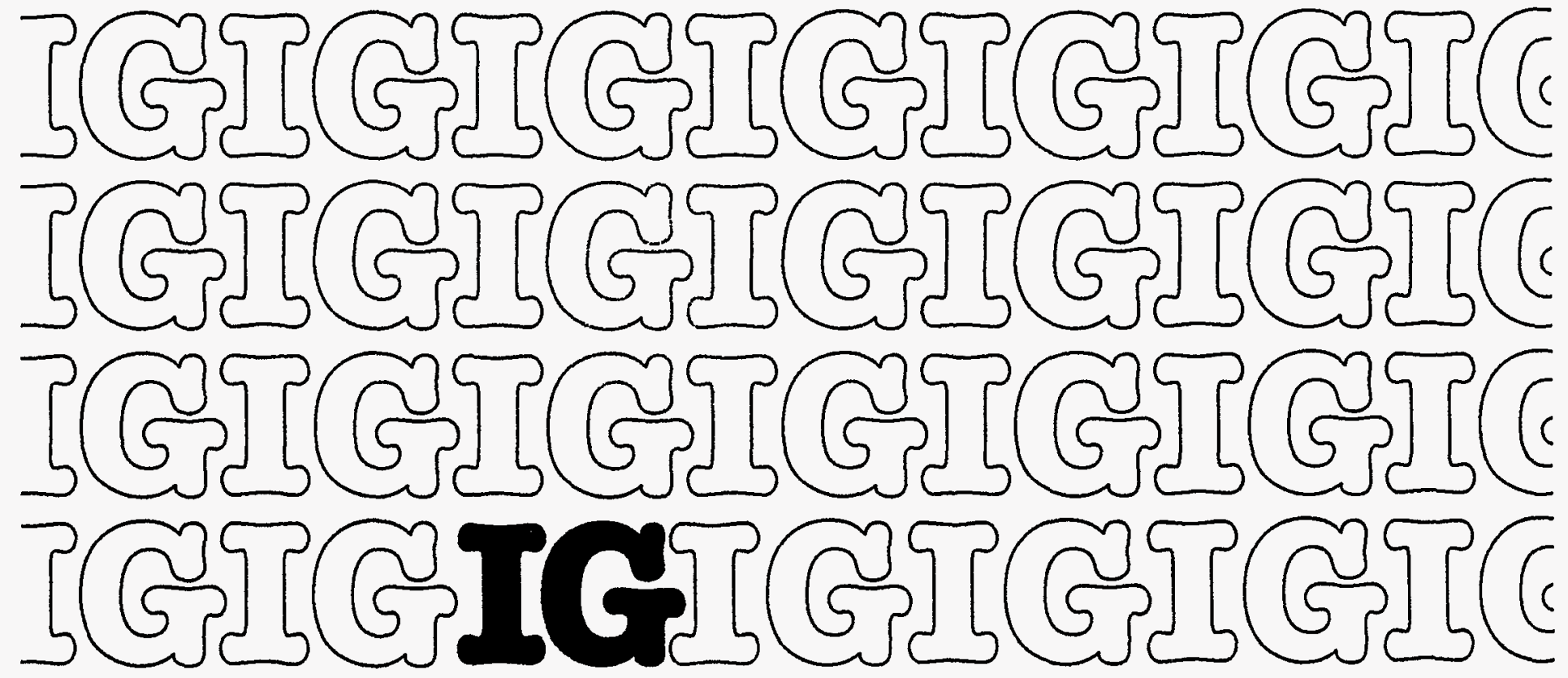


The Office of Inspector General wants to make the distribution of its reports as customer friendly and cost effective as possible. Therefore, this report will be available electronically through the Internet five to seven days after publication at the following alternative addresses:

\author{
Department of Energy Headquarters Gopher \\ gopher.hr.doe.gov \\ Department of Energy Headquarters Anonymous FTP \\ vm1.hqadmin.doe.gov \\ U.S. Department of Energy Human Resources and Administration \\ Home Page \\ http://www.hr.doe.gov/ig
}

Your comments would be appreciated and can be provided on the Customer Response Form attached to the report.

This report can be obtained from the

U.S. Department of Energy

Office of Scientific and Technical Information

P.O. Box 62

Oak Ridge, Tennessee 37831 


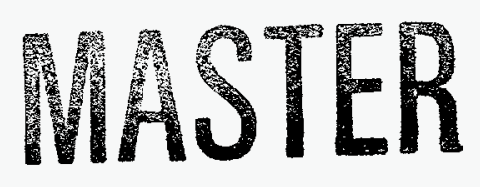

Report Number: WR-B-97-06

Date of Issue:
June 9, 1997
Western Regional Audit Office

Albuquerque, New Mexico 87185

DISTRIBUTION OF THIS DOCUMENT IS UNMMTED

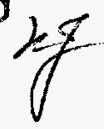




\section{DISCLAMMER}

Portions of this document may be illegible in electronic image products. Images are produced from the best avallable original document. 


\section{AUDIT OF RENOVATION AND NEW CONSTRUCTION PROJECTS \\ AT LAWRENCE LIVERMORE NATIONAL LABORATORY}

\section{TABLE OF CONTENTS}

$\underline{\text { Page }}$

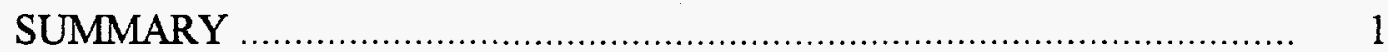

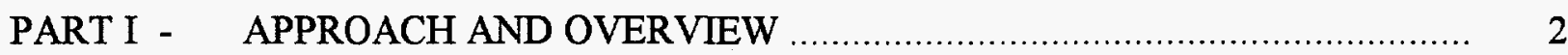

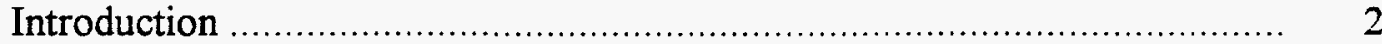

Scope and Methodology ................................................................... 2

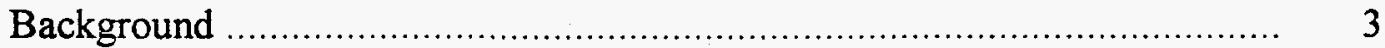

PART II - FINDING AND RECOMMENDATIONS …......................................... 5

Livermore's Proposed Projects ............................................................ 5

PART III - MANAGEMENT AND AUDITOR COMMENTS ……........................... 11 


\author{
U.S. DEPARTMENT OF ENERGY \\ OFFICE OF INSPECTOR GENERAL \\ OFFICE OF AUDIT SERVICES \\ WESTERN REGIONAL AUDIT OFFICE
}

\title{
AUDIT OF RENOVATION AND NEW CONSTRUCTION PROJECTS AT LAWRENCE LIVERMORE NATIONAL LABORATORY
}

Audit Report Number: WR-B-97-06

\section{SUMMARY}

The Oakland Operations Office (Oakland) is responsible for acquiring facilities needed to satisfy mission needs and to do so at the least cost to the Department of Energy (Department). The objective of the audit was to determine if proposed renovation and new construction projects at the Lawrence Livermore National Laboratory (Livermore) met mission needs while minimizing cost to the Government.

In pursuing three projects, estimated to cost over $\$ 78$ million, Livermore had not demonstrated that it had selected the best alternatives for meeting the Department's needs while minimizing cost. Livermore was able to pursue these projects because Oakland did not ensure that the laboratory had performed cost and benefit analyses of all alternatives. Further, Oakland did not establish benchmarks to assess the reasonableness of the total costs of designing, constructing, and managing these projects. As a result, it was likely that the Department was spending more than necessary on renovation and new construction projects at Livermore.

Although the projects met mission needs, we recommended that the Manager, Oakland: (i) require Livermore to perform analyses of expected costs and benefits for alternatives; (ii) evaluate the adequacy of Livermore's cost and benefit analyses of alternatives; (iii) establish benchmarks based on industry and other government agency cost data to assess the reasonableness of Livermore's total design, construction, and project management costs; and (iv) select the alternative that meets established needs at the least cost to the Government. Oakland agreed with the recommendations and will implement them starting with the Fiscal Year 1999 project submission and validation.

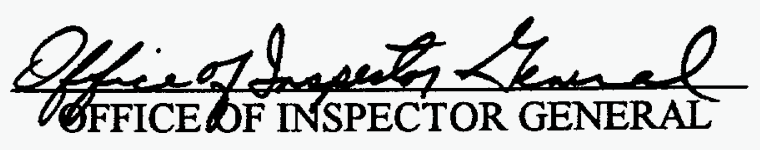




\section{$\underline{\text { PART I }}$}

\section{APPROACH AND OVERVIEW}

\section{INTRODUCTION}

The Department strives to perform its tasks at the least cost commensurate with quality results. Consistent with the Department's vision, Oakland should ensure that Livermore performs systematic analyses of expected costs and benefits of alternatives, and selects the least costly alternative to design, construct, and manage renovation and new construction projects.

Accordingly, the objective of this audit was to determine if Livermore's proposed renovation and new construction projects met mission needs at the least cost.

\section{SCOPE AND METHODOLOGY}

The audit was conducted at Oakland and Livermore from April to October 1996. According to a construction project line-item list covering Fiscal Years (FY) 1991 through 2005, Livermore had 43 renovation and new construction projects totaling over $\$ 1.5$ billion in various stages of planning or construction. The scope of the audit was limited to line-item projects which were planned, proposed, or funded for FY 1996 through FY 2001. Planned projects were those in the pre-conceptual design stage. Proposed projects were those where the conceptual design studies were under way or completed but the projects had not been funded. Funded projects were those that were approved for design, construction, project management, and had received funding. We judgmentally selected and reviewed eight projects totaling $\$ 161$ million. The eight projects included a planned renovation of an experimental building into office space, three planned phases of the major re-roofing of 11 buildings, a proposed combined fire station and medical facility, a proposed new facility for genomic and biology research, a proposed project to re-roof 4 buildings, and a funded contained-firing facility for a firing bunker.

To accomplish the audit objective, we:

- reviewed Office of Management and Budget (OMB) Circulars, and Departmental Orders;

- interviewed Departmental Headquarters, Oakland, and Livermore personnel responsible for managing, reviewing, and evaluating program funding and construction proposals;

- reviewed construction project documents, such as validation reports, project listings, and design reports;

- toured existing facilities and sites where construction projects were planned, proposed, or funded;

- reviewed the contract for performance objectives relating to management of facilities; 
- obtained an independent cost estimate from the U.S. Army Corps of Engineers (Corps) for the proposed combined fire station and medical facility project; and,

- obtained design, construction, and project management cost data for fire stations from three municipal fire districts.

In reviewing the eight projects, we determined if these projects were necessary to meet mission needs. Further, we examined whether Livermore evaluated alternative ways of meeting these mission needs, including any analyses of costs and benefits, to determine if Livermore identified the least costly alternatives. In order to determine whether the proposed budget for the combined fire station and medical facility project was the least costly alternative, we established two benchmarks. First, we requested the Corps, a Federal agency, to develop an independent estimate as a benchmark to evaluate the reasonableness of Livermore's total design, construction, and project management budget estimate for this project. We asked the Corps to base its independent estimate on the same conceptual design report that Livermore used to develop its estimate, and time period that Livermore used for starting and completing the design and construction of this project. We also requested the Corps to include all applicable overhead costs in the independent estimate. To arrive at a comparable estimate, we adjusted the Corps' estimate to account for (i) additional costs (such as costs for activation, standard equipment, project liaison, and reporting requirements) that Livermore would incur for this facility that the Corps would not normally include in a budget submission, and (ii) direct costs for requirements not clearly identified in the conceptual design report (such as additional underground electrical and mechanical work and relocation requirements). Second, we obtained total design, construction, and project management cost data from three municipal fire districts as an additional benchmark to evaluate the reasonableness of Livermore's budget estimate.

The audit was performed according to generally accepted Government auditing standards for performance audits and included tests of internal controls and compliance with laws and regulations to the extent necessary to satisfy the audit objective. We reviewed significant internal control procedures for evaluating the need, alternatives, and cost for renovation and new construction projects. Since we did not rely extensively on computer-processed data, we did not fully assess the reliability of that data. Because our review was limited, it would not necessarily have disclosed all internal control deficiencies that may have existed at the time of our audit. On October 7 through 9, 1996, the results of the audit were discussed with program and project managers from Oakland's Engineering and Facility Management Division, Oakland's Livermore Site Management Division, Oakland's Berkeley Site Office, and the pertinent officials from Livermore.

\section{BACKGROUND}

Livermore, operated by the University of California since 1952, is involved in multiple areas of research and development supporting the Department's missions in national security, science and technology, energy resources, and environmental quality. Livermore must periodically renovate existing facilities or build new ones to accomplish its missions or to provide infrastructure to support its missions. 
For example, in accomplishing the Department's mission in science and technology (biomedical science), Livermore will request approval and funding for the design, construction, and project management of the proposed genomic and structural biology facility. This project will cost about $\$ 40$ million and provide 80,000 square feet of laboratories, office space, and support areas. In 1995, Oakland validated and included this project in its FY 1997 budget submission. However, the Department did not approve nor include this project in the FY 1997 budget because of other priorities and limited construction funds. In May 1996, Oakland granted Livermore approval to resubmit this project for validation and inclusion in the FY 1999 budget submission.

In another mission-related project, Livermore received approval and funding to build the $\$ 49$ million contained-firing facility at Site 300 . Livermore will use this contained facility in support of the Department's national security Stockpile Stewardship and Management Program.

To improve its infrastructure, Livermore is pursuing the renovation of Building 431, estimated at $\$ 33$ million. The project involves converting a 1950's era high-bay experimental facility (five stories high) into an office building with a central atrium. The planned renovation will create a minimum of 180,000 net square feet of office and support space to house about 800 employees. Another infrastructure project that we reviewed was the combined fire station and medical facility project to be built at the laboratory's Site 300 . Livermore's estimated budget for this project, which will provide 8,500 square feet of space, is about $\$ 5.3$ million, based on its 1998 Field Budget Process submission. 


\title{
PART II
}

\section{FINDING AND RECOMMENDATIONS}

\author{
Livermore's Proposed Projects
}

\section{$\underline{\text { FINDING }}$}

The Department should renovate and construct only facilities that satisfy mission needs at the least cost. However, Livermore was pursuing three projects, estimated to cost over $\$ 78$ million, despite the fact that it had not demonstrated that the proposed approaches for the projects were the best alternatives for meeting the Department's missions while minimizing the cost to the Government. Livermore was able to pursue these projects because Oakland did not ensure that the laboratory had performed cost and benefit analyses of all alternatives. Further, Oakland did not establish benchmarks to assess the reasonableness of the total cost of designing, constructing, and managing these projects. As a result, the Department was at risk for spending more than necessary on renovation and new construction projects at Livermore.

\section{RECOMMENDATIONS}

We recommend that the Manager, Oakland Operations Office:

1. Require Livermore to perform cost and benefit analyses of alternatives.

2. Evaluate the adequacy of Livermore's cost and benefit analyses of alternatives.

3. Establish benchmarks based on industry cost standards or other government agency cost data to assess the reasonableness of Livermore's total budgeted costs to design, construct, and manage renovation and new construction projects.

4. Select the best alternative for meeting mission needs at the least cost.

\section{MANAGEMENT REACTION}

Oakland agreed with the recommendations. Detailed management and auditor comments are provided in Part III of this report. 


\section{DETAILS OF FINDING}

The Department's projects should satisfy mission needs at the least cost. According to the Department's February 1994 report, Making Contracting Work Better and Cost Less, the Department must ensure that its tasks are performed at the least cost commensurate with quality results. OMB Circular A-11 and Departmental Order 430.1 provide the control framework for implementing this principle by requiring the Department to justify renovation and new construction projects based on how the projects meet mission needs and to analyze expected costs and benefits.

\section{LIVERMORE'S ANALYSES OF ALTERNATIVES, COSTS, AND BENEFITS}

Livermore, however, was pursuing projects that it had not demonstrated to be the best alternatives for meeting the Department's mission needs at the least cost.

\section{Genomic and Structural Biology Facility}

Livermore's proposed $\$ 40$ million genomic and structural biology facility may not be the least costly alternative to meet space requirements for anticipated increases in biomedical workload. Livermore's justification for this project stated that existing facilities would be inadequate to absorb the additional workload created by the proposed doubling of funds to $\$ 49$ million over the next three years. Livermore, however, did not conduct detailed analyses of the costs and benefits associated with alternative ways of providing the space. Although Livermore program managers discussed some alternatives, the analyses of costs and benefits of the alternatives were not conducted. For example, the program managers discussed modular buildings as an alternative but then, without any cost analyses or cost comparisons, dismissed them as being not cost effective.

\section{Renovation of Building 431}

Renovation of Building 431 may not be the best approach to provide replacement office space at the laboratory. Livermore envisions that this renovation project would revitalize an underutilized asset (Building 431) and provide adequate office space for about 800 employees currently assigned to substandard facilities that are no longer considered economically reparable. The project has an estimated cost of $\$ 33$ million, plus or minus 50 percent. However, this renovation would create excess space because the office space per employee is more than allowed under the contractual space standard. Livermore's proposed renovation, for example, would create about 225 net square feet per employee. The contractual space standard, in contrast, is 165 square feet per employee or 132,000 square feet for 800 employees. By renovating 180,000 square feet, Livermore would have 48,000 excess square feet.

Livermore had not performed cost and benefit analyses of alternatives in determining how best to meet office space needs at the least cost. Such analyses are particularly important for a project like this that has a "soft" total estimated cost, which ranges from $\$ 16.5$ million to $\$ 44.5$ million. At $\$ 33$ million or below, the cost per square foot of office space may be similar to the cost of new construction. However, once cost begins to go above $\$ 33$ million, it could be less 
expensive to construct a new office building. Other alternatives to renovation could include the use of modular buildings.

\section{Fire Station and Medical Facility}

Livermore's budgeted cost of over $\$ 5.3$ million to design, construct, and manage the proposed fire station and medical facility project compared unfavorably with the Corps' estimate, as adjusted, of about $\$ 3.8$ million, a difference of about $\$ 1.5$ million. The Corps estimated it would cost them about $\$ 2.9$ million to design, construct, and manage this project. We added to the Corps' estimate (i) $\$ 420,000$ for standard equipment and activation costs and $\$ 156,000$ for Livermore's liaison and reporting costs, and (ii) $\$ 297,000$ for requirements that were not clearly identified in the conceptual design report. The $\$ 1.5$ million difference between estimates prepared by Livermore and the Corps generally involved about $\$ 1$ million of indirect cost allocations that are required by the Department's Budget Formulation Handbook and about $\$ 500,000$ attributable to escalation rates prescribed by the Department and a contingency factor based on Livermore's assessment of risk.

In addition to comparing Livermore's budgeted cost to the Corps' estimate, we also compared it to actual cost data for similar structures acquired by local governments in the San Francisco Bay Area. This benchmarking exercise disclosed that Livermore's budgeted cost compared unfavorably to costs incurred by three San Francisco Bay Area fire districts that built three new fire stations. On a per square foot basis, Livermore's estimated design, construction, and project management costs were more than double that of the actual design, construction, and project management costs incurred by the fire districts. Table 1 compares, by square foot, Livermore's proposed cost and the cost incurred by three fire districts for fire stations.

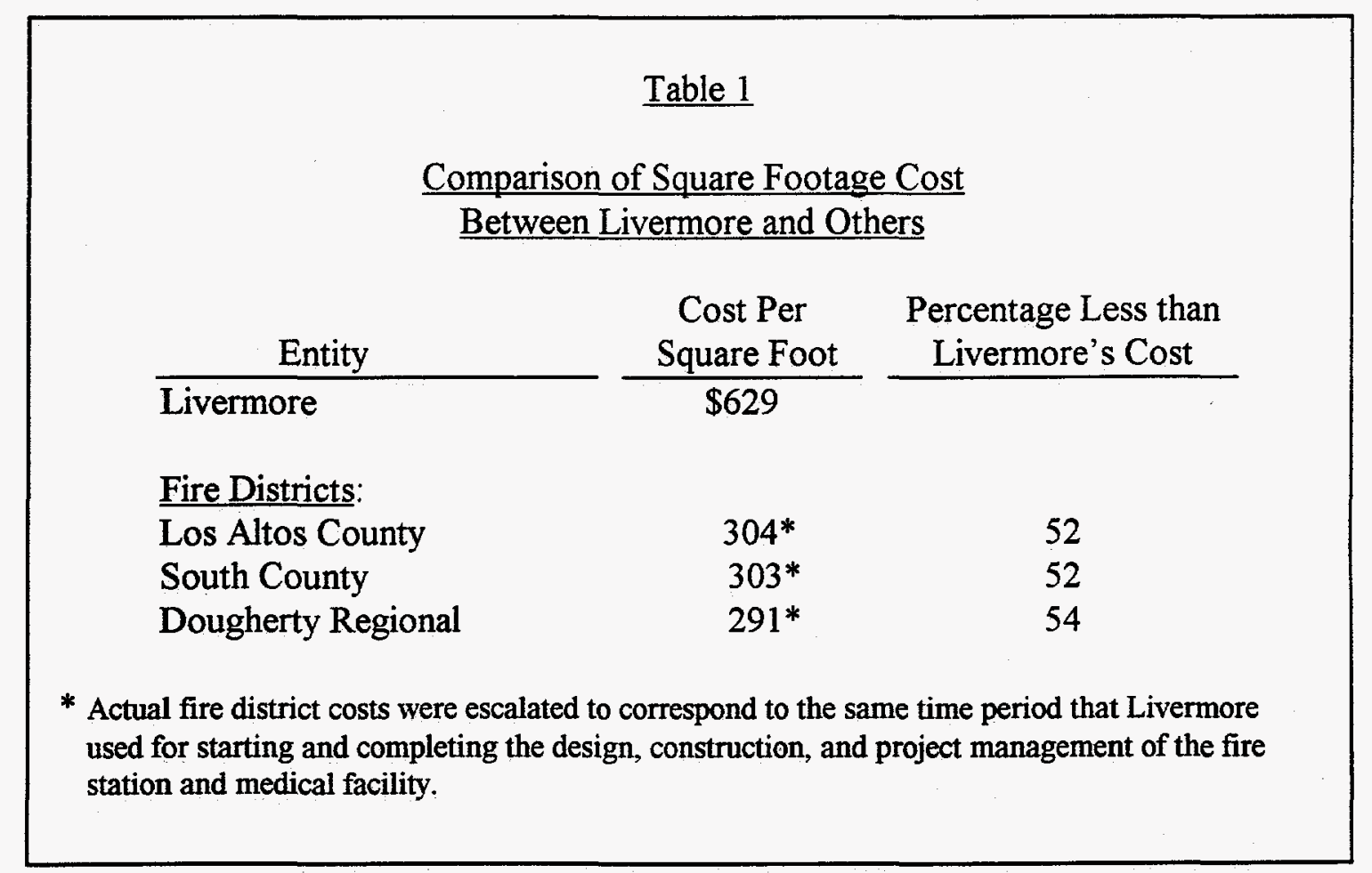


As Table 1 shows, Livermore's square footage estimated cost was the most expensive. Although the fire districts' costs were for the design, construction, and project management of fire stations only, Oakland's project manager stated there were no significant differences in industry square footage cost standards between a fire station and a medical clinic.

\section{ALTERNATIVES AND INDUSTRY STANDARDS}

Livermore's authority to manage construction projects from initial planning through construction does not eliminate Oakland's responsibility to (i) explore all alternatives and analyze the costs and benefits for each alternative, and (ii) establish benchmarks based on industry standards to assess the reasonableness of Livermore's total design, construction, and project management cost estimates. Both OMB Circular A-11 and Departmental Order 430.1 require Oakland to meet these responsibilities.

\section{Alternatives}

When the genomic and structural biology facility project was first validated in 1995 , Oakland did not ensure that Livermore had analyzed the costs and benefits of all alternatives. In May 1996, when Oakland approved Livermore's request to resubmit this project for validation and inclusion in the FY 1999 budget submission, the laboratory still had not performed cost and benefit analyses of alternatives. Oakland stated, after discussions with the Office of Inspector General (OIG), that it would request Livermore to perform cost and benefit analyses in determining whether this project or another alternative was the best option to meet the mission need.

For Building 431, Oakland was not aware that Livermore had not taken action to analyze the costs and benefits of alternatives in meeting replacement office space needs. Livermore was planning to submit this project to Oakland for approval to proceed with the conceptual design study in early FY 1997. As with the genomic and structural biology facility, Oakland directed Livermore to evaluate all alternatives to meet future office space requirements and to complete cost and benefit analyses in identifying the least costly alternative.

\section{Industry Standards}

Oakland had not established benchmarks, based on similar projects by other government agencies or industry, for assessing the reasonableness of Livermore's total estimated budget for the proposed fire station and medical facility. During project validation, Oakland evaluated the reasonableness of the direct cost estimate for constructing the building by comparing it to similar buildings completed by the U.S. Air Force and with industry square footage standards. In addition, Oakland (i) verified Livermore's direct cost estimate associated with project management and design and construction management by using General Services Administration Design and Construction Lookup Tables, and (ii) reviewed Livermore's utility construction estimate. However, Oakland did not evaluate Livermore's total cost estimate (direct and indirect costs) against industry standards in assessing the reasonableness of the total estimate and identifying alternatives for lower design, construction, and management costs for this project. 
In responding to a draft of this report, Oakland agreed to work with Departmental Headquarters to establish construction project benchmarks. However, Oakland expressed a preference to base its benchmarks on Departmental experience rather than that of other agencies. Our understanding of the Departmental position regarding the importance and usefulness of benchmarking and our audit work in this area suggest that this position is not consistent with the current Departmental focus. As stated in the Department's report, Making Contracting Work Better and Cost Less, Oakland needs to base its benchmarks on other governmental and private industry experiences to effectively assess the reasonableness of Livermore's total costs. To base its benchmarks on only Departmental experience does not meet the intent of the Department's position and could make it difficult for Oakland to establish performance requirements essential to identifying, verifying, and controlling costs of construction projects and helping the Department perform its tasks at the least cost commensurate with quality results.

The problem with basing benchmarks on Departmental experience is that it inappropriately confers a status of cost efficiency on the Department's activities. An example of this is architect and engineering costs within the Department. In September 1990, the OIG issued Report No. DOE/IG-0289, Departmentwide Audit of Architect and Engineering Design Costs, which concluded that the Department's architect and engineering costs averaged more than twice that of private industry. Six years later, not much had changed, based on the contents of Report No. DOE/IG-0387 (March 1996), Audit of Architect and Engineering Costs at the Idaho National Engineering Laboratory. That report disclosed that architect and engineering costs for 65 conventional construction projects (for example, warehouses, office buildings, and laboratories) at the Idaho National Engineering Laboratory (INEL) were 81 percent higher than comparable industry standards. When the INEL architect and engineering costs for 20 conventional construction projects were compared to the State of Idaho's design costs, INEL's costs were 62 percent higher than the state's. Therefore, establishing benchmarks based primarily on the Department's cost experience merely institutionalizes historic management practices.

The fire station and medical facility project demonstrates how the historical practice of keeping construction projects "in-house" at Livermore can lead to higher costs. In its response to the draft report, Oakland correctly pointed out that most of the difference between estimates prepared by Livermore and the Corps involved indirect, contingency, and escalation. Because Livermore was keeping the project in-house, it had to use its indirect rates, which were higher than the Corps'. Livermore also used its contingency and escalation rates, which were more than twice the Corps' rates, because the project was being kept in-house.

Oakland, and the Department as a whole, need to implement the commitment in the April 1994 Strategic Plan to pursue new approaches that challenge the status quo. Oakland should consider alternatives, such as outsourcing, that may in the long term help the Department achieve reduced budgetary outlays for renovation and construction projects. If the Corps' cost estimate for the fire station and medical facility is indicative of savings to be achieved through outsourcing, Livermore's total costs should decline over time as projects are outsourced and the amount of indirect costs attributable to Livermore's construction activity declines. The OIG is not advocating that Oakland use the Corps to design, construct, and manage the fire station and medical facility project. The Corps is presented as one alternative source that Oakland should have explored in determining how much the Department should reasonably budget and pay for the project. 


\section{POTENTIAL BENEFIT OF ANALYZING ALTERNATIVES}

We concluded that Oakland has an opportunity to realize savings in its renovation and new construction projects. Analyses of costs and benefits of all alternatives could result in savings to the Department through cancellation or rescoping of planned and proposed projects. Given Livermore's $\$ 1.5$ billion of planned and proposed renovation and new construction projects, the savings could be substantial. While our benchmarking was limited to one project, that of the fire station and medical facility, the results indicated that alternatives to keeping construction projects in-house at Livermore may have to be pursued if costs are to be reduced in the long term. 


\section{$\underline{\text { PART III }}$ MANAGEMENT AND AUDITOR COMMENTS}

Oakland agreed with the recommendations and will implement them starting with the FY 1999 project submission and validation. Management and auditor comments on specific recommendations follow.

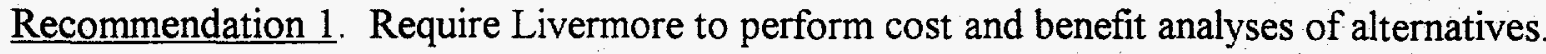

Management Comments. Concur. Oakland required Livermore to perform cost and benefit analyses on all reasonable alternatives in response to direction from Departmental headquarters for the FY 1999 project validations and submissions. These validations and submissions took place during the audit. Livermore performed the cost and benefit analyses based on a graded approach.

Auditor Comments. Management's comments are responsive to the recommendation.

Recommendation 2. Evaluate the adequacy of Livermore's cost and benefit analyses of alternatives.

Management Comments. Concur. To evaluate the adequacy of Livermore's cost and benefit analyses, Oakland required Livermore to perform cost and benefit analyses. Livermore is using the National Institute of Standards and Technology computer program, "Building LifeCycle Cost." This is the standard program used by the Department of Defense and recommended for use by the Department's Committee on Cost Methods Development.

Auditor Comments. Management's comments are responsive to the recommendation.

Recommendation 3. Establish benchmarks based on industry cost standards or other government agency cost data to assess the reasonableness of Livermore's total budgeted costs to design, construct, and manage renovation and new construction projects.

Management Comments. Concur. Oakland will work with the Office of Project and Fixed Asset Management, Office for Field Management, in Departmental Headquarters in establishing proposed benchmarks for construction projects based on other government agencies' and private industry's experience. Oakland would prefer to use Departmental related benchmarks. However, Oakland will likely use the benchmarks established by the Office of Project and Fixed Asset Management because the Office's benchmarks presumably will become the Department's standard.

Auditor Comments. Management's comments are responsive to the recommendation.

Recommendation 4. Select the best alternative for meeting mission needs at the least cost. 
Management Comments. Concur. In response to recommendation 1, Oakland will select the best alternative for meeting mission needs at the least cost based on Livermore's cost and benefit analyses.

Auditor Comments. Management's comments are responsive to the recommendation.

\section{ADDITIONAL MANAGEMENT COMMENTS}

Management Comments. In responding to drafts of this report, Oakland stated that the Corps' estimate to design, construct, and manage the fire station and medical facility project did not include traditional indirect costs, escalation costs, and contingency allocations, all of which are mandated by the Department. After comparing the Corps' estimate of direct construction costs against the Livermore's estimate for the project, Oakland believed the direct construction costs were similar. The additional cost required to pay for the indirect costs, escalation rates, and "zero-risk" based contingency costs account for the difference between the Corps' estimate and Livermore's estimate.

Oakland disagreed with the implication that, if cost reductions could be rationalized for the fire station and medical facility project and the costs and benefits of alternatives for other projects had not been analyzed, the entire Livermore out-year capital program was subject to suspicion. Oakland disagreed particularly with applying this implication to Livermore's $\$ 1.5$ billion of planned and proposed projects because there was only about $\$ 300$ million of out-year proposed new projects once ongoing construction projects, including the National Ignition Facility, were removed.

Management did agree with the OIG's assertion that Oakland should continue to look for new ways to design and build facilities to reduce initial construction costs as well as life-cycle facility costs. Prior to the initial meeting with the OIG, Oakland's engineering and procurement staffs started to explore state-of-the-art private sector processes for facility design and construction procurement. Oakland and Livermore had jointly developed a new "best qualified" construction contract process to competitively select the best qualified builder. Oakland anticipated this process would help create a design and construction team dedicated to building a project on time and within budget by improving communications, reducing construction changes, and eliminating claims. Oakland is currently using this process to construct the contained-firing facility project.

Auditor Comments. Oakland's and Livermore's actions to implement the "best qualified" construction contract process to competitively select the best qualified builder should have a positive impact on costs. However, the results of the auditors' benchmarking of the fire station and medical facility showed that other approaches to renovation and construction, such as outsourcing, offer the potential for reducing expenditures. Although the amount and timing of savings cannot be predicted with precision, opportunities for reducing expenditures will be lost if these other approaches are not considered objectively.

Management Comments. Oakland stated that the OIG identified only three examples out of 43 projects reviewed where Livermore was pursuing projects that it had not demonstrated to be the best alternatives for meeting the Department's mission needs at the least cost. Oakland further 
noted that the OIG did not assert that any of the projects were not the best alternatives, only that this was not demonstrated, that is, alternatives defined, cost-benefit analyses performed and the determination documented. In addition, the OIG acknowledged that the projects met mission needs.

Auditor Comments. We did not review all 43 projects. Rather, we judgmentally selected eight projects, totaling $\$ 161$ million, out of the 43 projects for review. The costs associated with the three projects reported on total over $\$ 78$ million, or 49 percent of the projects dollars reviewed. Although we acknowledged that the mission needs existed, we questioned whether Livermore had demonstrated that the questioned projects were the best alternatives for meeting the Department's mission needs at the least cost. Therefore, the audit results caused us to question whether there was adequate assurance that Livermore was pursuing the best alternative. 
IG Report No. WR-B-97-06

\section{CUSTOMER RESPONSE FORM}

The Office of Inspector General has a continuing interest in improving the usefulness of its products. We wish to make our reports as responsive as possible to our customers' requirements, and therefore ask that you consider sharing your thoughts with us. On the back of this form, you may suggest improvements to enhance the effectiveness of future reports. Please include answers to the following questions if they are applicable to you:

What additional background information about the selection, scheduling, scope, or procedures of the audit or inspection would have been helpful to the reader in understanding this report?

What additional information related to findings and recommendations could have been included in this report to assist management in implementing corrective actions?

What format, stylistic, or organizational changes might have made this report's overall message more clear to the reader?

What additional actions could the Office of Inspector General have taken on the issues discussed in this report which would have been helpful?

Please include your name and telephone number so that we may contact you should we have any questions about your comments.

Name

Date

Telephone

Organization

When you have completed this form, you may telefax it to the Office of Inspector General at (202) 586-0948, or you may mail it to:

Office of Inspector General (IG-1)

Department of Energy

Washington, D.C. 20585

ATTN: Customer Relations

If you wish to discuss this report or your comments with a staff member of the Office of Inspector General, please contact Wilma Slaughter at (202) 586-1924. 